\title{
Words about Images: Coordinating Community in Amateur Photography
}

\author{
REBECCA E. GRINTER \\ College of Computing, Georgia Institute of Technology, GVU Center-TSRB, 85 Fifth Street, \\ NW, Atlanta, GA 30332-0760,USA (E-mail: beki@cc.gatech.edu)
}

\begin{abstract}
This paper describes how the adoption of digital technologies by two amateur photography communities created coordination challenges. Digital technologies disrupted the classification schemes used not just to sort images into groups for competition, but also served to coordinate the community itself. In opening up the classification scheme, members were able to see and reflect on the sources used to establish the definitions that sorted images and organised their practices not just locally but more widely across various boundaries. Without having words about images, both amateur photography communities would have struggled to coordinate.
\end{abstract}

Key words: amateur communities, classification

\section{Introduction}

In the last few years, digital cameras and associated imaging technologies have entered mainstream usage - sales of digital cameras have now surpassed those of film and some manufacturers have ceased to make the latter. The increased popularity of digital pictures has been further accelerated by the integration of cameras into cellphones. The increased ownership and use of digital imaging technologies have a variety of implications for CSCW. Most visibly, we have already seen media and scholarly reports about the role of images in MMS and photoblogging communications (Koskinen et al., 2002; Kurvinen, 2003).

Yet, digital images have other implications for CSCW. Beyond imagebased communication, pictures as an art form facilitate collaboration between those who produce them - the photographer - and those who consume them - the audience (Becker, 1982). In this paper, I focus on collaboration between image producer and consumer, and how digital imaging technology disrupted that collaboration forcing those who wished to coordinate action to re-establish their communications.

This paper presents data from two studies of amateur (hobby) photographers. The studies show that while the adoption of digital technologies provided new opportunities for amateur photographers to collaborate, these 
same technologies presented significant challenges for the definitional and coordination practices of the amateur photography community. Specifically, the arrival of these digital technologies challenged the accepted definitions of what it meant to take, make and print an image. This caused problems for the amateurs because it was those definitions that were used not only to sort images but also coordinate activity.

In the next section, I review the literature about collaboration around images. That is followed by an introduction to the two communities studied and the methods used to study then. The following sections describe the challenges that digital imaging technologies created within each community, and how the members resolved them and re-established the definitions used to sort their images. The paper concludes by presenting three CSCW implications of studying amateur communities: the ability to broaden the analytic focus of collaboration away from the setting of action to the structure of interaction, the consideration of aesthetic criteria for coordination, and opening up the narratives that not only surround the image-in-communication, but are embedded into the image-in-taking and image-in-making.

\section{Collaboration around images}

Despite the availability of cameras for over a century, relatively little is known about practices surrounding the taking and sharing of images (Sontag, 1979; Chalfen, 1987; Bourdieu, 1990 (orig. 1965); Lutz and Collins, 1993; Frohlich et al., 2002; Rodden and Wood, 2003; Frohlich, 2004). This puzzling omission has become more noticeable in the last few years as both CSCW and HCI researchers have increasingly encountered and begun designing for systems that include digital images. What little has been learnt about people's image practices can be broadly grouped into two themes: image sharing as meaning making and image organisation as classification. In this section I explore these two themes in more detail.

\subsection{IMAGE SHARING AS MAKING MEANING}

The relationship between image sharing and the making of meaning has been studied in two distinct settings: media photographic consumption and consumers' domestic practices. By media photographic consumption, I mean the study of the role of media organisations - in particular newspapers and magazines - and how the public reads the pictures in their publications. It is an orientation to members of the public, and their own practices of taking and sharing images with family and friends that have been the target of studies of consumers. Consumers in this case being the people who purchase cameras and take images. 
Examination of the consumption of photographs through media outlets has not tended to report on the practices of specific individuals but instead take up societal debates (e.g. Sontag, 1979). For example, in their analysis of 600 images from National Geographic magazine, Lutz and Collins (1993) show how the magazine carefully crafted a vision of what life in the third world was like for its readers. They found that images in the magazine tended to show life in the third world as exotic and did not include scenes such as those showing obvious poverty. Consequently, readers were encouraged to take away interpretations of third world that emphasised the exotic-ness of life in those countries, while downplaying the difficulties.

The adoption of digital imaging technology has an important place in the discussion of photographs in the media, one that centres on the perceived ease of manipulation of the pictures. The role of potentially manipulated images in the reporting of 'truth' has been widely debated, often when altered examples enter the spotlight themselves, such as when actors and actresses sue magazines claiming that their image has been altered (National Union of Journalists, 1996). This debate clearly highlights the relationship between images and meaning: manipulated images manipulate meaning. Further, the tone of the debate suggests that manipulating images is, societally speaking, problematic.

The intentional manipulation of pictures to shape meaning has a much longer history than that of the digital camera and image alteration software. For example, during Stalin's era, group pictures of party members would be altered - sometimes more than once - as the various individual's political fortunes waned. In some cases, images of individuals were crudely scratched out of current textbooks, but in many other cases more sophisticated alteration techniques were used to reprint the revised image with its new group composition (King, 1997). In this particular instance, the relationship between an image and the truth was being quite intentionally manipulated to reflect the new political realities.

By contrast with the examination of images as consumed through media publication, studies of consumers' use of pictures have highlighted the nuances of individual sharing practices. In an early study of consumers' practices, Chalfen (1987) describes what he calls a "home mode of pictorial communication." This home mode of communication reveals householders image sharing practices in great detail. For example, he describes how householders select appropriate audiences (close family, distant family, friends) for various types of images, how the telling of stories surrounds the shared viewing of images, and behind that the construction and reconstruction of reality. These narratives go beyond descriptions of where and when a picture was taken, to include the image's place in family history (see also Chalfen, 1991).

More recently, two studies of consumers' photographic sharing practices have included digital as well as traditional print images (Frohlich et al., 2002; 
Crabtree et al., 2004). The same theme of story telling as a means for shared reality construction permeates both studies. Both studies also emphasise that the person telling the story designs it for the recipient. For example, Frohlich et al. (2002) distinguished between two types of narrative: story telling and reminiscing. Story telling focused on describing the picture to people who were not present at the time the image was taken, while reminiscing occurred among people who were present at the time of capture. What remains common across the detailed examples presented in both studies is that the image producer and the audience worked together to arrive at a mutual understanding of what the photograph represented. ${ }^{1}$

The studies by Frohlich et al. (2002) and Crabtree et al. (2004) also highlight an adoption challenge for digital images. Specifically, for co-present sharing, consumers seemed to prefer using a traditional print to on-screen viewing. Indeed, images that started life as digital were often printed for sharing purposes. Frohlich et al. (2002) also described how for the consumers studied, photographs ceased to be digital when printed, they became treated as traditional images.

Despite the different foci for studies of media image consumption and consumers' photographic practices, the theme of meaning making in picture sharing emerges consistently. The relationship between image sharing and meaning making emphasises images as communicative artefacts. Further, these studies show how digital technologies have entered, somewhat problematically, into the communications. In the case of photographs in the mass media, digital technologies increase the possibility of manipulation and the consequent distortion of the truth as communicated through publications. For consumers, digital images (whether manipulated or not, neither study comments on the degree of consumer image alteration) need to be bought into a conversation, which often requires transforming them into printed form.

\subsection{IMAGE ORGANISATION AS CLASSIFICATION}

The rise in popularity of digital images (whether taken or scanned in) has led to another line of study focused on the sorting and classifying of images. These studies fall into two rough groups: consumers sorting their pictures at home and the classification of large image libraries for a variety of users. The studies of consumers again focus on individuals' domestic photographic practices. The studies of classification of image libraries have tended to start with the library at hand, and consequently emphasise the sorting of those images in the context of the occupation or interest of those accessing the library.

Studies of consumers such as those by Frohlich et al. (2002), Crabtree et al. (2004), and Rodden and Wood (2003), observe that consumers sort 
'good' images from 'bad' ones, not based on the technical quality of the image itself (is it sharp or well composed) but whether it captures an important event. Good images tend to be those that would become part of a narrative, in other words shared with others, so those get sorted into places where they are easily accessible.

These same studies also point to the sorting challenge that digital photography presents. Frohlich et al. (2002) and Rodden and Wood (2003) both reported that people tended to have folders of unsorted images on their hard drives. People rarely if ever annotated individual images, although they did typically annotate the folder or 'roll' (a metaphor for the aggregation of images in Rodden and Wood's prototype) with a general description of the contents. Rodden and Wood also provided a variety of visual sorting mechanisms, but found that few people used those features. Frohlich et al. (2002) offer one reason why consumers' may not spend much time sorting their digital images out which is that the 'good' images get transformed into printed ones and then merged into the physical sorting scheme.

All the studies of consumers describe individuals who would prefer to have more organised photograph collections. Sentiments of regret, or the difficulty of finding time to prioritise classifying images, appeared numerous times in these studies. That said images remained relatively unorganised.

Relatively unorganised image libraries also represent the focus of systems and studies designed to classify pictures for a variety of purposes. One significant challenge for computerised image classification is generating enough textual metadata for each image so that the sorting criteria become embodied into the system. Studies of people who use image libraries (for example, art students who use images of paintings, or architects who review images of buildings) find that the text associated with an image does not typically provide enough information to generate useful results in a searching mechanism. The problem of image sort has lead to solutions that attempt to generate the sort metadata either automatically (Yee et al., 2003) or manually (von Ahn and Dabbish, 2004) or some combination (Lieberman et al., 2001; Sarvas et al., 2004). In the case of manual classification, another challenge emerges, which is to find a means of motivating people to participate in the classification of images. One successful means has been to turn image classification into a game that emphasises fun over the actual classification process (von Ahn and Dabbish, 2004).

Both types of study suggest that despite the potential for providing technological support for image classification, much more needs to be done to determine and generate the appropriate sorting schemes. Technical and social problems create strong barriers to classifying images. For the CSCW community these difficulties should not come as a surprise, because the challenges created by classification in coordination have long been a focus of research (Bowers, 1992). Many computer applications rely on categories as 
an integral part of the provision of functionality to an end user. The area in which categories have perhaps received the most discussion concerns workflow systems (Suchman, 1994; Winograd, 1994).

Classification has also come up in discussions of coordination mechanisms and articulation work (Schmidt and Bannon, 1992). Specifically, classification schemes can be used in support of articulation work - all the work required to coordinate action among individuals (Strauss, 1985; Gerson and Star, 1986). The work of Bowker and Star $(1991,1999)$ highlight how different types of classifications support interaction among multiple user consistencies in such a way that each group can provide data.

This paper builds on the themes of classification, but applies them to an instance where a community had a well-developed scheme for sorting images out. Amateur photographers, faced with large collections of images - generated when individuals submitted photographs for competition - had mechanisms for classifying images as belonging in certain groups. Beyond just sorting the images, the classification scheme also served as the mechanism by which the community coordinated their activities. The use of classification to coordinate distinguishes amateur photographers from other photographic audiences such as consumers or the general public. Collaboration did not focus on meaning making via image communication, but by classification that made it possible to simultaneously organise images and actions.

It was into this established set of classification practices that digital imaging technologies arrived. The adoption of these technologies by amateurs eventually forced the community to open up its classification scheme for inspection because digital images initially disrupted the schema used to sort images out. This paper describes how new technologies disturbed the preexisting categories and how the community then needed to have words about images in order to re-establish a working classification system. Next, I describe the two communities studied and the methods used.

\section{The study}

The data in this paper derives from long-term participant observations of two amateur photography communities. Amateur photographers differ from both professionals and consumers. Amateurs typically differ from professionals by not relying on picture taking for financial gain. Amateurs earn little if anything from the sales of their pictures. Indeed, some definitions of amateur photographer prohibit a person from earning more than $15 \%$ of their annual income from photography sales. Despite the widespread popularity of amateur photography, these communities remain unstudied. In this section, I describe the two communities studied and the methods used to gather and analyse the data. 


\subsection{THE COMMUNITIES}

Before I could study either community, I needed to acquire various materials and competencies. First, and foremost, I needed to purchase a Single Lens Reflex (SLR) camera. SLR's like many compact cameras use 35-mm film. However, SLR's differ from compact cameras by giving the user more control over the picture produced in two ways. First, they have interchangeable lens systems that allow the user to take more types of pictures. Second, while many SLR's - like consumer cameras - provide a fully automatic mode they also provide a variety of semi-automatic and manual modes. Amateur photographers typically do not use the fully automatic mode.

Having acquired a SLR camera (a Nikon N70/F70 in this case) I needed to understand how the different semi-automatic and manual modes worked. This involved learning about the relationship between aperture, exposure, and film, and how to manipulate the multiple variables to produce different results. Finally, I needed a collection of images to bring to the meetings and digital representations to share in the online forums.

The first community studied, PhotoClub, met in a physical space twice a month. ${ }^{2}$ The study took place over the course of 2.5 years. During that time, PhotoClub had between 25 and 35 members. I attended most of the regularly scheduled meetings and participated in a variety of club outings during that time.

The second community, AmateursOnline, was an online community that was organised by a magazine publisher. AmateursOnline was the online discussion forum for the publisher's amateur photography magazine PhotoNews. At the time of initial subscription, PhotoNews had not started AmateursOnline. Consequently, I was able to participate in the early formation of the community that then grew to approximately 1000 registered participants. Of course, and like many online communities, active participation was considerably less, but still enough to generate new content within an hour of logging off and request the creation of new discussion lists and auxiliary forum. The number of discussion lists grew from 10 to 28 by the time I left. The study took place for 1.5 years, but the magazine subscription lasted for 3 years.

\subsection{METHODS AND ANALYTIC DISTANCE}

One challenge that studies like this pose concerns how to gather and analyse data, while participating in these communities. In this case, the challenge was to maintain a critical stance and avoid 'going native', while simultaneously trying to understand the transition from newcomer to full member through my own experiences. Six techniques were used to ensure analytic distance. 
First, the importance of timely field notes increased. Following Lofland and Lofland's (1995) recommendation about how to maintain distance, I kept detailed logs of each meeting of PhotoClub and copies of many of the message threads from AmateursOnline. I supplemented these field notes with other printed and electronic materials that captured some of the difficulties technologies were generating for image categorisation. For example, as judging guidelines or competition entry criteria changed, so new proposals were handed out for review at club meetings, which I kept as a means of capturing steps in the process of redefining various categories.

Second, I supplemented participant observation by talking with members about their experiences in other clubs. It was quite common for PhotoClub members to belong to several camera clubs (that provided a different mix of activities for their members). These discussions allowed me to get away from my experiences by hearing about experiences in different settings.

Third, I was able to take advantage of natural breaks in activity to engage in analysis. Most camera clubs have a season of activity that does not include the summer. The summer being the period when many members travel and acquire new material for the next season. These natural breaks provided me with three opportunities to 'get away' from the direct experience of participation, and conduct some initial analysis as recommended by Strauss and Corbin (1990).

Fourth, periodically I took opportunities to talk with professional colleagues (outside of the camera club and not interested in photography) about my experiences. These talks allowed me to discuss my ideas and more importantly get outsiders feedback. Questions that my colleagues posed during these discussions (whether they were professional empirical researchers or not) helped me see outside my own experiences (also recommended by Lofland and Lofland, 1995).

Fifth, I conducted a few sensitising exercises in the style of breeching experiments. I would present materials for judgement that would explore the boundaries of definitions proposed for various image categories. I describe these in the paper.

Sixth, and finally, the majority of the analytical analysis did not begin until I departed from both communities. Field notes and initial analytic write-ups suggesting themes and directions within the data were put aside, and I returned to life as a civilian photographer - with a rather nice camera during that time. After many months past, I reviewed my notes again and where I did not have data, I made specific investigations through contacting amateurs and/or lurking on AmateursOnline. I also used secondary sources including those generated by other amateur photography clubs, magazines, and websites to triangulate the documented experiences. 


\section{PhotoClub}

In this section, I describe how digital technologies opened up the classification scheme for discussion within PhotoClub and more broadly. First, I describe. PhotoClub's organisational structure and competition practices. The organisational structure and competitions situate the role of the classification scheme within the community. Then I turn to an examination of the definitional difficulties wrought by digital technologies.

\subsection{WELCOME TO PHOTOCLUB}

\subsubsection{Organisational Structure}

PhotoClub members met twice a month during all but the summer months. Each meeting lasted between 2.5 and 3.5 hours and consisted of a variety of activities, such as technique improvement sessions and club members showing their work. However, PhotoClub set aside many meetings throughout the year for photographic competitions.

PhotoClub was a member of a large amateur photography organisation that I call RegionalClubs. RegionalClubs was the organisation that provided opportunities for members of PhotoClub to compete against other clubs on behalf of PhotoClub. RegionalClubs membership of 40 clubs came from a population of around 6 million people. In addition to competitions, RegionalClubs was one source for classifying images into competition categories (that was used by RegionalClubs for its competitions, but could also be adopted by member clubs for their own internal club competitions), judges for competitions, and guidelines for judging.

Finally, membership in RegionalClubs allowed PhotoClub members to participate in a nation-wide society that I call NationalSociety. This connected a small club like PhotoClub (and others like it) to a national amateur photography scene. NationalSociety, like RegionalClubs, was another source for competitions. More significantly, from the perspective of this study, it was another source for definitions of competition categories and judging guidelines, which embodied and reinforced the classification schemes used to sort images and structure community. Both RegionalClubs and the NationalSociety were organisations that PhotoClub turned to when they faced their own difficulties with definitions.

\subsubsection{Competitions}

PhotoClub held photographic competitions throughout the year. A number of evenings were set aside for competition at the club. Even on non-competition nights, rules and judging guidelines would often be discussed. Competitions provided the richest source of information about the challenges that digital technology presented. In this section, I explain the competition process. 
Both PhotoClub and RegionalClubs organised members into two classes for competition: beginners (Class B) and advanced (Class A). All new members started in Class B. Success in Class B could lead to promotion to Class $\mathrm{A}$ in the following year.

In addition to sorting members, PhotoClub used categories to sort images for competition. The first sort was by medium: print versus slide. Prints were next sorted by maker-made (made by the photographer) and commercial. Other sorts to reduce the number of entries to a manageable size included sorting by size of image (small print, large print) and black and white versus colour.

Unlike prints, PhotoClub did not sort slides at all. Instead, it held one general competition (separated into two Classes A and B). However, RegionalClubs did sort slides, so for the members of PhotoClub to participate as individuals and on behalf of the club, they needed to master the slide categorisations. RegionalClubs sorted slides around topic including Nature, Journalism, and Creative.

The competition process (for both prints and slides) consisted of three judges each viewing and rating the slides in a Class (A or B) on a scale of 3 to 9.

"Score of Three. This is an obvious non image, as for example, when a flash does not go off, or the shutter was released by mistake and only a blurry shot, without any real subject results.

Score of Nine. An image that scores 9 is an exceptionally strong image i.e. true photographic excellence. It need not be a perfect image, just a very, very, strong image."

After each image was shown the cumulative total of the judges' scores was announced and the next image shown. ${ }^{3}$ Typically competitions used a series of viewings, first to whittle down the entries to a small subset that were then reviewed again to select the winner and runners up.

Beyond each competition, the point score received by entrants was used to rank that entrant against their competitors. At the end of the photographic year, each entrant's total score (the sum of all scores for all an individual's competition submitted images) was computed. These scores were used to rank members in each class, and declare an overall competition winner in each class. If the overall point score was high enough, a member of Class B might also be promoted to Class A for next year's competition. More subtly, total scores were also used by members to show how their technique had improved among competition years. Some members responded enthusiastically to the sense that their picture taking skills had improved (a motivation to join the club initially), while others wondered whether overall technique had improved or whether they had better senses about what images made good competition material. 
Competitions followed this structure in both PhotoClub and RegionalClubs. RegionalClubs also held club-level competitions. Each member club could select slides from its individual members and those would be entered into competition (in the same manner) at the club level. At the end of the year, total scores for clubs would be computed, and so clubs could be ranked against each other for their overall photographic excellence in competition.

Competitions then, in addition to serving as a good night's entertainment, had a longer-term purpose in PhotoClub and RegionalClubs: they evaluated and ordered the members and clubs. For the members competing individually, and the club-level competitions, the point score reflected the submitter's competency level over a length of time. Given the level of reward and risk (loss as an individual and loss as a club by lowering the club's point average at the RegionalClubs level) that competitions afforded, it is not surprising that digital technology created difficulties when it threatened traditional definitions used to sort images into competition categories.

\subsection{TECHNOLOGY AND CATEGORIES IN COMPETITION}

During the time of the study, home computer ownership increased generally. This was reflected within PhotoClub as more members purchased computers, printers, software, cameras, and connected to the Internet. For a considerable percentage of the membership, computers, printers, and so forth formed part of their daily working life. So, more and more members began experimenting with digital image manipulation and making, and gradually this began to affect PhotoClub in the form of discussions about what to do with the products of these digital processes. In the next two sections, I describe the challenges that image manipulation created for slide competitions, and how image making affected printmaking.

\subsubsection{Image Manipulation}

One challenge that computer technology raised for RegionalClubs and PhotoClub centred on the ability to easily manipulate images. Discussions about manipulation at RegionalClubs began when those interested in digital techniques began to realise its consequences for the definitions that formed the basis of many image categories. These early warnings, so to speak, were delivered at RegionalClubs gatherings informally, and also flowed back to clubs like PhotoClub through the RegionalClubs representatives they had.

Discussions intensified as members with the appropriate technology began to convert their digital experiments into slide and submit them for competition. These early entries into competitions acted as the catalyst for escalating the discussions about what to do about these new image types. Conversations about digital images shifted from informal discussions to 
agenda items for discussion at RegionalClubs, and so they took centre stage. The result of this shift was that the RegionalClubs governance took on the responsibility of beginning to redefine the categories to include a determination about digital production and manipulation where necessary, and the members of local clubs such as PhotoClub were asked to vote on various rulings.

It was in response to these rulings that the discussions at PhotoClub began. The club's representative to RegionalClubs often began the evening meeting with an update on a new ruling that was explicitly designed to accommodate digital imaging within the scope of a particular slide category. PhotoClub was asked to discuss and return with a decision about whether the club supported the ruling.

The Journalism slide category drafted a ruling that allowed digitally taken images to be submitted for competition, but prohibited any manipulation. At the time, the Journalism slide category accepted images that reported on current events of local, national, or international interest. RegionalClubs argued that they should allow digitally taken images because digital cameras support the goal of timely documenting of current events (partially by avoiding film processing lags as well as the ability to quickly send the picture off). By pursuing this line of argument, RegionalClubs was orientating towards professional photojournalism (where timeliness proves critical for news publication). However, since the most serious competitors in this category often produced pictures for local newspapers (for free), a number of them had already turned to digital technology, and it was also in RegionalClubs own interest to keep their competition base.

The Journalism category also used arguments from professional photojournalism to prohibit digital image manipulation. Using examples of debates raging more broadly about the dangers of manipulated images in news reporting, they set their policy to reflect this concern. The generation of the policy was uncontested at PhotoClub. The discussion was short because most of the members agreed that both elements of the ruling were appropriate for the Journalism category. The brevity of the discussion also of course was a tacit agreement that it was appropriate for the Journalism category to draw from the most ethical of journalistic standards as a means of setting the standard for what could be submitted and judged in that category. It was ultimately a short, but salient reminder of not just the category construction itself, but how the category would most likely evolve (by following 'the best' of professional journalism).

Unlike the Journalism category that drew on professional standards, the Nature slide category relied on strict and elaborate details about the image contents to set its policy. The foremost principle of inclusion in the Nature category was that the submitted slide could not contain any evidence of the hand of man. While that sounds deceptively simple, it ruled out many 
potentially natural seeming scenes. For example, a picture of a wild collie dog would not qualify as Nature because collies are an artificial breed. On the other hand, wild roses growing in a garden would likely be acceptable (as long as there was no evidence of cut grass or artificial breeds of flowers and trees that would indicate the presence of a human).

The Nature committee of RegionalClubs set a digital policy that matched that of the Journalism category. Digitally taken images were acceptable, but any form of manipulation was grounds for exclusion from the Nature category. In this case, the concern about manipulation stemmed from the ability to easily turn a collection of nearly Nature pictures into Nature acceptable pictures by deleting evidence of man (even by cropping it out, let alone manipulating it out).

The Nature ruling was also presented to the members of PhotoClub. Although the ruling passed at PhotoClub, the discussion was not as supportive as it had been for the Journalism category. With the discussion of the Nature ruling came the discussion about whether the category (irrespective of the presence of digital) had too strict a definition of Nature. Indeed, at PhotoClub, members had a more forgiving definition of what constituted Nature. For example, I entered an image that was taken in the woods on the Upper Peninsula of Michigan - an area of the United States that is largely wilderness - that contained a little evidence of a footpath. It showed successfully in that category, although one of the judges who was not a member of PhotoClub observed during his assessment that it was not strictly a Nature image.

Although some members of PhotoClub fully concurred with the rules surrounding submissions in the Nature category, other members found the strict definition of nature tedious at best and difficult to realise in practice. Nature was difficult for many members of the club to find, especially those who only had the weekends to practice their hobby or limited resources to travel to the Western United States where Nature seemed more abundant (or man less present). So, digital imaging took second place to a discussion about Nature itself, the same type of conversation that had previously broadened the Nature category at PhotoClub. PhotoClub members ultimately used the same solution, allowing RegionalClubs to continue with its digital policy and strict determination of what constituted Nature, while PhotoClub members kept their own definition. Those PhotoClub members with digital equipment whose own definitions of Nature matched RegionalClubs continued to participate in the competition with their unaltered, Nature-only images. Those PhotoClub members who felt that RegionalClubs had taken Nature too far, continued to participate with both traditional and digital images in PhotoClub competitions. Interestingly, PhotoClub did not set any specific guidelines about the role of digital technology in its Nature competitions. 
RegionalClubs admission of digital images in Journal and Nature could be characterised as a cautious embrace of digital technology. The Creative slide category could not take such a position. Creative slides - also known as altered reality - emphasise image manipulation. Although it sounds like a category that might have been born out of image manipulation software, it existed prior to digital technology. ${ }^{4}$ For example, one traditional alteration technique creates an impressionistic image by taking two images (one in focus and one out of focus) and then sandwiching the two slides together in a single frame. Based on its mission, the Creative category was thus obliged to accept digitally manipulated images. Consequently, it was the Creative category that challenged RegionalClubs to go into considerable detail about what constituted an acceptably manipulated image.

Again, as part of the definition process RegionalClubs sought input from PhotoClub members. It was in the course of discussing the Creative category that PhotoClub examined the details of digital image production. The committee that produced the Creative category's response to digital technology ultimately defined what it meant to make a digital picture and the relationship between making an image and taking an image within amateur photography. Consequently, it was in the Creative category that the most detailed discussions about what digital technology meant for amateur photography emerged.

Discussions begun with an analysis of what a Creative image was. Unlike the other categories, a Creative image was comprised of elements that could have distinct origins. For example, taking a landscape photograph and adding another element, such as a full moon from a different picture, would produce a final image with two distinct elements. So, the question of what it meant to make an image turned on understanding how each of the multiple elements were produced, and what the contribution of the person submitting the final image to competition was to the generation of each of these elements.

Members agreed that the use of non-copyrighted (let alone copyrighted images) images available on the Internet should be prohibited. This was seen as a statement that the person submitting the slide had to have a hand in not just the making of the image from the parts, but also the making of the individual parts themselves. The Creative category reinforced the belief, widely held, but perhaps not well articulated until this discussion, that amateur photography is about not just the making of an image but also the taking of an image and that these can be distinct processes.

There was less consensus about the balance of photographer made photographic elements versus photographer made computer generated elements. So, although image taking was considered an integral part of the Creative category just what it extended too was a source of tension. At PhotoClub, members could agree that some percentage of the over all elements had to be taken photographically, but others argued that part of the goal of the Creative category was to emphasise the 'capture' of other 
elements that could be computer generated. The pro-computer generated elements people argued that the final image would be more interesting, more Creative, when it combined non-photographic elements that could be produced on the computer. Other members felt that the Creative category, and amateur photography more generally, was about the photographic method, not other forms of artistic method, and argued against their inclusion. At the end of the study RegionalClubs had disallowed computergenerated images, but the ruling seemed uncertain, and members were planning to discuss it next year.

The entry of digital images into Journalism, Nature, and Creative categories temporarily opened up the categories for inspection by revealing the criteria used to establish and maintain them. This temporary opening, which was by and large over at the end of the study with the exception of the Creative category, created a phenomenal workload for those amateur photographers tasked with the assignment of finding ways to simultaneously allow members with digital equipment to participate in categories, while retaining equity for the traditionalists. Solutions allowed PhotoClub and RegionalClubs to interact, through the shared definitions that supported slide transfer from local club to regional interclub competitions. Mainly this occurred through agreement with shared definitions, but in the case of Nature, it also happened where PhotoClub members took their own definition and recognised its difference and, in that case, managed what got sent to RegionalClubs Nature competitions as a separate process.

\subsubsection{Image Making}

It was members' adoption of home colour printers that presented one challenge for print competitions. The computer and printer combination opened up the category of 'maker-made' prints for discussion. Now, the category of maker-made asked people to compare the making of 'darkroom' and 'lightroom' prints.

Traditional maker-made prints go through two steps. First, the film is developed. This step in the process requires control skills: mixing an exact chemical solution, heating the solution to appropriate temperature, keeping the film and solution clean to avoid scratches on the negatives. By contrast, printing the paper image from the negative, while still needing some degree of control also requires creativity. Mastery of a variety of techniques allows the maker to shape the look of the final image: how saturated the dark colours are, how much tonal variation exists, and so forth.

So, the adoption of digital technologies raised the question of whether an image printed in the 'lightroom' (a term used to describe the digital darkroom) required a comparable combination of control and creativity skills. The answer to this question was the subject of much discussion over the course of the club year at PhotoClub. The outcome of this discussion was a 
decision on whether digital prints could be entered as maker-made prints in the same competition.

The discussion about maker-made prints started when a group of lightroom enthusiasts wanted PhotoClub to hold a print competition where they could enter their work. At that time, PhotoClub did not have enough members who made traditional prints to sustain any type of print competition at the club level, although members did enter traditional prints into RegionalClubs competitions. The discussions began quietly, as questions to the members about whether other people were interested in having a print competition that included digitally made images. Initially, too few members had computers and associated technologies and the discussions did not gain much momentum.

As more members acquired computers, printers and photo manipulation software, so a large enough group of members wanted to have a print competition. At this point, the discussion shifted from being a question of critical mass, and towards the comparison between darkroom and lightroom image making techniques. Now, the members of PhotoClub needed to decide whether control and creativity were adequately present in lightroom work.

On the question of control, digital enthusiasts used two arguments. First, when images were scanned in from film-based originals, they argued that keeping the scan free of dust and scratches was analogous to keeping a traditional film development environment clean. People unfamiliar with scanning processes, and consequently more questioning, were eventually convinced when shown pictures of poorly scanned images.

The second line of argumentation was greeted more readily, since it turned on something all members were familiar with, the difficulties associated with setting up computers. Digital enthusiasts argued that the process of calibrating a printer so that it printed the exact colours as seen on the screen was excruciatingly difficult, but critical. In order to produce prints that reflected the maker's intent, the print-maker had to control the colours as printed otherwise changes made on the desktop would be in vain. Many people, even those who did not have computers personally, seemed well aware of and very accepting of arguments about computer mastery as being something that required considerable skill.

The digital enthusiasts handled the question of creativity differently. Rather than trying to make comparisons, as in the case of control, they took an approach that argued that it was a new type of creativity that distinguished digital from traditional printmaking. In the case of traditional printmaking, the opportunities to explore creative options typically arise during the development of the print. This limits the number of techniques that can be applied. By contrast, photo manipulation software allows the maker to continue to add effect after effect indefinitely. So, those interested in seeing digital prints be entered alongside maker made ones argued that the measure of creativity for digital images was that their maker had shown 
restraint and picked a small and complementary set of manipulation techniques. Aesthetically speaking, the definition of digital print creativity turned on knowing when to stop.

Taken alone, this line of argumentation might not have stood. It seems unclear whether the ability to create and the ability to stop creating can be compared. However, both the digital enthusiasts and the other club members (who could not be described as against the submission of digital prints, but wanting explanation about the place of those prints) relied on other practices to refine this line of argumentation. Specifically, they turned to a sub-categorisation of prints into two kinds: straight and manipulated.

The separation into two categories provided a definition of just how much manipulation was acceptable and sorted specific techniques. For example, a slight softening of the image or a colour enhancement (to increase saturation) fell into the category of straight image making. By contrast, many of the bolder filtering techniques available through software, such as rotating parts of the image constituted a manipulated image. The manipulated category ended up being analogous to its slide counterpart, Creative.

Together, arguments that categorised the creativity in maker-made prints, as well as showing how control existed in digital manipulation were sufficient to convince the membership not just to start a print competition, but participate in it. The discussions, and the decisions that came out of them also formed the basis for the judging guidelines, as well as the submission sort. So, PhotoClub began a print competition that allowed digital maker-made prints using the following guidelines about what constituted a maker-made print:

"A maker-made print is one whose content and final form is created by the original maker and no one else.

A commercial print is a print produced by someone other than the original maker."

However, these definitions did not resolve all the classification problems surrounding the difference between a maker-made and a commercially made image. In two sensitising experiments, I produced two "maker-made" images in different circumstances. In both cases I began by taking an image on film. In the first experiment, I printed that image at a local camera shop that had a machine that supported instant scanning and printing of the image. I asked that the staff not help me during the scanning and printing of the image. In the second case, the image was scanned and printed, but this time on equipment that my employer owned. Again, I was the only person involved in the process of scanning and printing. I submitted both prints, and an explanation of the processes used to generate them, as maker-made since I had created them.

Both images created much discussion and ultimately both were resubmitted in the commercial print categories. The print made on my employer's 
equipment was recategorised because the equipment belonged to my employer and that other employees had done all the work to set up and maintain the scanning and printing facilities. Consequently, I could not claim that I had set up and maintenance skills. This experiment had the effect of illuminating that support skills in addition to printing skills were considered a part of the work of making a digital print.

The print made at the camera shop was reclassified on similar grounds. However, it caused more heated discussions about what it meant to 'own' equipment. The concern was that part of the price of scanning and printing could be a 'temporary' lease of the machine itself. One reason why that was an attractive argument to make some types of commercial leasing an acceptable part of maker-made prints was the practice of leasing other types of equipment such as studio lights, cameras, lenses, and printing equipment. Ultimately, the leasing argument was deferred on the grounds that the majority of leasing occurs at the image taking stage and not the image making stage. Should that change, this category will likely be opened up again for inspection.

The ability to make images digitally opened up the print-based competition categories for discussion. The discussions surrounding making turned on revisiting the question of what it meant to have the skill and expertise to produce a final image. Then, once that was understood in both the traditional and digital case, the conversation turned to whether the two could be equitably compared.

\section{AmateursOnline}

AmateursOnline is the web-based online community hosted by the amateur photographic magazine PhotoNews. The online community is organised as a series of topics, each of which contains discussion threads. AmateursOnline, like PhotoClub, also had to sort out digital technology, which they did through the categorisation of their topic lists. However, unlike PhotoClub, AmateursOnline was simultaneously capitalising on those same technologies to form their community. In this section, I describe how AmateursOnline dealt with the challenges of classifying digital images, while leveraging technologies to introduce the traditional institutions of amateur photography to an online forum.

\subsection{TOPIC CATEGORISATION}

Although PhotoNews hosts AmateursOnline, it is the online community members that often argue for new topics (although PhotoNews' web 
administrators add them into the community area). The categorisation of digital technologies has featured heavily in their discussions and often played a role in generating new topic. In this section, I describe the formation of the lightroom and general computer problems topics.

Initially, AmateursOnline had a topic devoted to darkroom. After some time, members began to argue for separating traditional from digital developing and printing discussions, by asking for a separate lightroom topic to be created. Members argued that they individually were either interested in dark or lightroom skills and finding discussions that they wanted to participate was difficult because of the blurring of the two in a single topic. Although, the darkroom topic members had tried to get people who started new discussions to indicate in the subject header whether it was relevant to dark or lightroom, this had not been successful. So, people interested in both traditional and digital techniques argued for the separation. Eventually, this led to the formation of the lightroom topic: a place for discussing digital printmaking.

Lightroom was the second digital topic after Digital Equipment. Digital Equipment was one of the original topics launched with AmateursOnline, and discussions focused on reviews of various technologies with a view to inform members' purchasing decisions. Discussions included technical specifications, usability, price performance, as well as compatibility of various hardware and software products.

Despite the presence of these two digital topics, the members of AmateursOnline soon demanded a third list. Three months after the lightroom topic was established another campaign began for a 'general computer problems' topic. The members who argued for this third topic, wanted to see discussions about computer difficulties that did not pertain to either purchase decisions or lightroom technique move out of those topics. A discussion that emerged when a member posted that he was having trouble accessing the AmateursOnline website from his new computer was one example cited as a reason to start this third topic. The discussion generated lots of responses, and even spawned other discussions, as members tried to help the person find out why AmateursOnline was not accessible to him. After several days, and about 50 messages, it emerged that the installation of a new firewall was causing the problem.

The establishment of the third topic, General Computer Problems, gave AmateursOnline members a forum for help with their computer problems. At the same time, it also served to sort out three types of digital discussions: purchasing technologies, digital imaging techniques, and general problem solving. By means of these three topics digital 'talk' was ordered on AmateursOnline; however, categorising discussion was not AmateursOnline's only engagement with digital technology. 


\subsection{CLUBHOUSE: CREATING AN ONLINE CLUB}

In addition to topics, perhaps unsurprisingly, the members of AmateursOnline wanted to share their images. This led to members forming a second site, which I call ClubHouse. Although AmateursOnline could share images in their discussions, the system was designed for text. As a text-based chat system it allowed images to be uploaded in line with conversation, but the emphasis and priority was on the written word. Moreover, the system did not provide a mechanism to easily group pictures into collections. The problem of online collections was solved by a member (not PhotoNews staff) who established ClubHouse.

ClubHouse (a different type of web-based system based on web systems that support the online sharing of photographs with remote family and friends) supported the presentation of images in galleries. So the members of AmateursOnline began to share collections of their own images with others with the expectation of receiving feedback. The next use of ClubHouse was to use the image gallery to support discussions. For example, one person wanted to know about Agfa Scala, a slide film that produces black and white positives. Another member read and responded to the post with her experiences of the film, and also uploaded some scanned shots taken with Scala to a ClubHouse gallery.

Finally, AmateursOnline members came to use ClubHouse for competitions. Unlike PhotoClub and RegionalClubs, AmateursOnline did not debate the role of digital technologies in their monthly competition in the same way. All images, in one sense, were digital. To focus the competition AmateursOnline used a content-based theme for each month such as the colour red, water and decay. This mirrored the competition practices of PhotoNews, which also held a competition each month. One competition discussion AmateursOnline had concerned how to set the theme to be broadly inclusive of the membership. For example, the theme of 'Snow' would be fine for Canadian readers in January, but out of reach for New Zealanders in that month, and for South Africans more generally.

AmateursOnline began through the shared experience of reading PhotoNews and the shared ownership of computers and Internet access. Supported by PhotoNews, the members of AmateursOnline began to participate in the categorisation of the discussion lists that formed their community. Through these processes they found the means to absorb digital technologies into their talk online as well as their practices of getting online to talk. The formation of ClubHouse marked a shift away from words about images to integrating images into the community. What began as image-sharing experiences has broadened to include other amateur practices, most recently competitions. 


\section{Discussion: Words about images}

The need to classify has been long recognised within CSCW, and the sociological traditions that inform it (Bowker and Star, 1999). Studies of work settings show that classification schemes provide a mechanism for widely distributed groups, with potentially different agendas, to share information and coordinate action with each other. In this regard, amateur photographers function in a similar manner.

This study showed that amateur photographers combine image sharing and image organisation in order to collaborate, not just locally with each other, but more broadly (either through a hierarchy of clubs that goes all the way to national level or via the Internet). Specifically, amateur photographers use the classification of pictures as their means of sharing images - through the establishment of shared definitions that support their competition and communication practices.

I also described how the integration of digital technologies including cameras, scanners, printers, and photo manipulation software, temporarily exposed their classification scheme for examination, not just by myself, but by the community. In one sense, the photographers in AmateursOnline, RegionalClubs, and PhotoClub temporarily ceased to be central members of the community, by being forced to revisit the questions that newcomers to their communities often had. However, unlike newcomers who engage in legitimate peripheral participation by moving beyond just learning about a topic such as photography but learning to be an amateur photographer (Lave and Wenger, 1991; Brown and Duguid, 2000), those central members of the community were trying to redefine their classification system to be able to continue to coordinate action meaningfully. The committees of RegionalClubs, the responses of PhotoClub, and the topic classification discussions of AmateursOnline had the sense of urgency that comes with recognising that until the definitions of what constitutes an acceptable image (or discussion), have been resolved, competitions cannot be easily held. Without competitions, and the shared sense of action, the community could not continue to function effectively.

A focus on classification has also illuminated the varying sources that amateur photographers use in their classification scheme. In particular, in making decisions about what constituted an acceptable image, the amateurs drew on three different types of resource: professional communities, content, and process. In the case of Journalism, the amateurs set their own definitions according to their beliefs about the professional journalistic world. They did not, however, talk with active professional journalists (some amateurs may be retired ones, but there were no currently active professional journalists to my knowledge at PhotoClub or RegionalClubs), but drew on their own beliefs about the standards that that community would set for its work. In some senses, they drew their definition of what was acceptable from their 
aspirations of the craft of professional journalism, rather than the day-to-day details of professional journalism.

The hand of man principle used in the Nature category was enforced over the content of the image. The principle was derived from another type of external focus, to a discipline of study, Natural History (although they did explicitly exclude archaeology and anthropology). Instead of being oriented to how the professionals in that community would act with images (as in the case of Journalism), the Nature category considered its images not just a demonstration of composition and other photographic skills, but also competency in Natural History more generally. In some competitions, but not all, a Nature slide would be accompanied by a title that explained what the subject matter was including any Latin names of species in the picture. In other words, Nature was not just about photography, but also about demonstrating the competency of natural historical knowledge. This mastery of Natural History was extended to digital images.

Creative, and printmaking discussions turned on a different means for classifying images, the photographic method itself. In making determinations about whether digital techniques could be considered equitable, discussions focused on elements of the photographic process. In these discussions, the photographic method was depicted as a scientific-technical process (requiring control and precision in the heating and mixing of chemicals) but also an artistic process of making the printed image exhibit a greater creative range of tone and light.

The tension between the technical and artistic elements of photography binds amateurs to professional fine-art photographers. In the early 1900s, the technical aspects of the photographic process led to photography being characterised as a lesser art form focused on recording 'information' rather than interpretation (Hughes, 1997). In his book, Art Worlds, Howard Becker (1982) describes how art worlds - groups of producers of art, its consumers, and critics - work together to define the boundaries of what is acceptable. The initial struggle for fine art photography was to be included not just rhetorically into the world of fine art, but into the practical, organisational world of museum exhibition, name recognition, and potential financial reward.

Amateur photographers do not occupy the fine art world. Nor, do they occupy the professional - wedding, fashion, journalism - paid-labour photography world. Yet, in the definitions that they use to classify their images and consequently coordinate actions, they draw from all these sources. Not just directly, through examination of other photography communities' practices, but more indirectly through an examination of the photographic method itself. By revisiting and attempting to balance the scientific-technical and aesthetic elements of the photographic method, 
the amateur photographers are making decisions about where they as a community want to be, which recognises both types (fine art and professional) as having relevance to their own practice, but simultaneously, participating in the same conversations as many other photographic groups have done before them. Finally, it is worth observing that the one, and possibly largest group of photographers that amateurs do not draw definitions from, are consumer photographers. Amateurs, like professionals and fine arts photographers, distinction their practice from the bulk of photographs taken. To be amateur then is not to be an 'amateur' but to have some knowledge and skill in photography.

HCI and CSCW research has long focused on the relationship between technology and communities. The most commonly studied form of that relationship comes from the analysis of what Mynatt et al. (1997) term networked communities: those groups using technology to overcome distance. Bulletin boards, email distribution lists, USENET, MUD's, MOO's, and virtual environments have all provided opportunities for people to overcome distance and form new communities (see for example the following collections, Kiesler, 1997; Smith and Kollock, 1999; Churchill et al., 2001). AmateursOnline follows in this tradition, with the community adopting technologies to facilitate collaboration and communication at a distance. It is also AmateursOnline that highlights an important adoption distinction. AmateursOnline adopted digital technologies, not just as amateur photographers, but also to communicate about amateur photography. For example, in their digital talk, they wanted separation among different techniques such as darkroom and lightroom. In their practices of competition, they accepted darkroom (scanned in after printing) and lightroom work in the same way as PhotoClub. AmateursOnline adopted digital technologies twice, once for talking about digital technologies and once for practicing amateur photography. As digital technologies become increasingly common among individuals, will other networked communities also have this dual but distinct adoption of technology, for coordination and communication?

More generally, CSCW has not yet seen a focus on amateur communities (see Bogdan (2003) as an exception). Yet, the study of amateur communities offers several possibilities. First, an amateur community functions because people want to coordinate with each other, often over great distance, and with considerable personal expense involved. Technologies, of all types play a critical role in this type of organisation. Not just the Internet, or the cameras and printers of PhotoClub, but for some communities, such as the Amateur Radio enthusiasts, esoteric communications equipment. They offer opportunities to study communications and coordination in situations where that is not only desirable, but also critical to the function of the community. 
Moreover, the study of amateur communities provides an opportunity to experiment with different analytic frameworks. In the shift from the office, to the home, or to a public space, the role of physical space has continued to play a significant role in the interpretation of action and interaction. Yet, to understand PhotoClub, or RegionalClubs in terms of the places it met would not provide much insight into the mechanisms of interaction of these communities. Moving away from physical or virtual setting, and the role of space (Harrison and Dourish, 1996) in facilitating place allows the exploration of other analytical perspectives such as that provided by a focus on classification. Further, this study also shows that classification as coordination occurs away from wage-labour settings, and opens up the question of what other 'recreational classification' schemes for collaboration exist.

Finally, given that most studies of CSCW have focused on paid labour, it is not surprising that questions of what to design have turned on providing systems that support the nuances of work. In some respects, this study mirrors a number of those kinds of finding. In discussions about lightroom technique, expertise with and mastery of computing generally turned out to matter as a demonstration of competency in printing digital images.

Yet, mastery and expertise also arose in a different sense, that of artistic expression. In one case, computers make too much possible, and artistic judgement was expressed by members of PhotoClub as knowing when to stop. Away from questions of skill, PhotoClub and RegionalClubs members were also tackling questions about the ability of photographers to put new types of artistic content into their images, entirely computer-based elements. Questions about computer-generated art can be seen in one sense as being focused on an individual's interaction with the computer, and perhaps not a matter for CSCW. However, to return to the notion of an art world, the question of whether to admit computer-generated art extended well beyond an individual's ability to produce an image. Again, because images coordinated community, and allowed these amateurs to participate in their art world, this question took on group significance.

This paper began with a focus on image communications. Among consumers images are used to tell stories, whether those images are film-based prints shared around the coffee table, or digitally captured and communicated via blogs or MMS. The focus of much of the story-telling research has been to capture the verbal communications around those stories. By contrast, communications around images as they are shared, during competition, do not form the central coordination mechanism for amateur photographers. Rather, the classification scheme, and the resources that it draws on, has established (and re-established) the conventions for action. By conventions, I mean the established practices that allow amateur photographers to determine what type of image they have created: Creative, Nature, Maker-made and so forth. 
In his study of consumer photography, Chalfen (1987) also observes conventions surrounding what types of pictures get taken, of whom, and when. Chalfen's book suggests that even for consumers, behind narratives of imagesin-use, other 'stories' about images-in-taking also exist. For example, stories about what types of images ought to be captured (location, occasion), and their form and content. Yet, very little is known about what these conventions of images-in-taking are among consumers, and even less is known about how digital technologies have influenced or changed these practices. As imagebased electronic communications in a variety of forms looks set to grow, understanding these conventions of images-in-taking as part of the collaborative process among producer and audience seems of vital interest to CSCW.

\section{Conclusions}

This paper has presented data from the study of two amateur photography communities: PhotoClub and AmateursOnline. In each community, digital technologies challenged definitions of what it meant to take and make images. These definitions mattered, because they were used not just to classify images, but also to coordinate actions within groups and across geographical boundaries.

Consequently, each community opened up its definitions not just to the researcher, but also to the community members themselves. The classification scheme in use relied on broad array of external sources to establish the grounds for an acceptable image in a variety of category. Over time, debates about skill, acceptable manipulation, copyright and clip art, as well as the general troubles with computers, became regular discussion topics among members. At the heart of all these debates was a need to re-establish the criteria for how to sort images out: what to include and reject, and how to compare fairly. Behind the need to sort images out was the need to maintain community practices, to find ways for images to be shared and members to judge and be judged. Ultimately, it was words about images that served to reestablish the classification scheme used to sort images and structure community action.

This paper has argued that the study of amateur communities has much to offer CSCW. Analytically, it offers the opportunity to understand how technologies can be used to communicate among members, and coordinate action, in different but complementary ways. It shows that amateur communities have a wealth of coordination needs, stemming from their need to function as a community. It also opens up discussions about collaborations around artistic processes - as opposed to the creative processes used in the work place - and highlights the role of conventions in images-at-taking, which may potentially exist in consumers' photographs. 


\section{Acknowledgments}

I would like to thank PhotoClub, RegionalClubs, and AmateursOnline for helping me understand recreational classification as well as how to improve my pictures. I'd like to thank those who read this paper and provided thoughtful and helpful comments.

\section{Notes}

${ }^{1}$ Most recently, reports of MMS usage and photoblogging also reveal that story-telling is a significant form of sharing practice (Koskinen et al., 2002; Kurvinen, 2003).

2 Names have been changed to preserve anonymity.

${ }^{3}$ One feature of the review process is that the judges critique your work in front of you. It would be akin to having the reviewers of your papers stand up and present their review to you in person. Judges are encouraged to be constructive, but it can be pretty painful.

${ }^{4}$ This category most reflects the long history of highly skilled photographic alteration that existed prior to the invention of image manipulation software.

\section{References}

Becker, H.S. (1982): Art Worlds. Los Angeles, CA: University of California Press.

Bogdan, C. (2003): IT Design for Amateur Communities, Doctoral Dissertation Royal Institute of Technology, Stockholm, Sweden.

Bourdieu, P. (1990 (orig. 1965)): Photography: A Middle-Brow Art. Palo Alto, CA: Stanford University Press.

Bowers, J. (1992): The Politics of Formalism. In M. Lea (ed.): Contexts of Computer-Mediated Communication. New York, NY: Harvester Wheatsheaf, pp. 232-261.

Bowker, G. and S.L. Star (1991): Situations vs. Standards in Long-Term, Wide-Scale Decision-Making: The Case of the International Classification of Diseases. In J.F. Nunamaker and R.H. Sprague (eds.): Proceedings of the Twenty-Fourth Annual Hawaii International Conference on System Sciences, Hawaii, 1991. IEEE Computer Society Press, pp. 73-81.

Bowker, G.C. and S.L. Star (1999): Sorting Things Out: Classification and Its Consequences. Cambridge, MA: MIT Press.

Brown, J.S. and P. Duguid (2000): The Social Life of Information. Boston, MA: Harvard Business School Press.

Crabtree, A., T. Rodden and J. Mariani (2004): Collaborating Around Collections: Informing the Continued Development of Photoware. In Proceedings of the ACM Conference on Computer Supported Cooperative Work (CSCW 04), Chicago, Illinois, November 6-10, 2004. ACM Press, pp. 396-405.

Chalfen, R. (1987): Snapshot Versions of Life. Bowling Green, OH: The Popular Press, Bowling Green State University.

Chalfen, R. (1991): Turning Leaves: The Photographic Collections of Two Japanese American Families. Albuquerque, NM: New Mexico Press.

Churchill, E.F., D.N. Snowdon and A.J. Munro (eds.). (2001): Collaborative Virtua Environments. Heidelberg, Germany: Springer-Verlag.

Frohlich, D.M. (2004): Audiophotography: Bringing Photos to Life with Sounds. Dordrecht, Netherlands: Kluwer Academic Publishers. 
Frohlich, D.M., A. Kuchinsky, C. Pering, A. Don and S. Ariss (2002): Requirements for Photoware. In M. Twidale (ed.): Proceedings of the ACM Conference on Computer Supported Cooperative Work (CSCW 2002), New Orleans, LA, November 16-20, 2002. New York, NY: ACM Press, pp. 166-175.

Gerson, E.M. and S.L. Star (1986): Analyzing Due Process in the Workplace. ACM Transactions on Office Systems, vol. 4, no. 3, pp. 257-270.

Harrison, S. and P. Dourish (1996): Re-Place-ing Space: The Roles of Place and Space in Collaborative Systems. In M.S. Ackerman (ed.): Proceedings of the ACM Conference on Computer Supported Cooperative Work CSCW '96, Cambridge, MA, November 16-20, 1996. New York, NY: ACM Press, pp. 67-76.

Hughes, R. (1997): American Visions: The Epic History of Art in America. New York, NY: Alfred A. Knopf.

Kiesler, S. (ed.) (1997): Culture of the Internet. Mahweh, NJ: Lawrence Erlbaum Associates.

King, D. (1997): The Commissar Vanishes: The Falsification of Photographs and Art in Stalin's Russia. New York, NY: Owl Books.

Koskinen, I., E. Kurvinen and T. Lehtonen (2002): Mobile Image. Helsinki, Finland: IT Press.

Kurvinen, E. (2003): Only When Miss Universe Snatches Me: Teasing in MMS Messaging. In Proceedings of the International Conference on Designing Pleasurable Products and Interfaces (DPPI 03), Pittsburgh, Pennsylvania, June 23-26, 2003. ACM Press, pp. 98-102.

Lave, J. and E. Wenger (1991): Situated Learning: Legitimate Peripheral Participation. New York, NY: Cambridge University Press.

Lieberman, H., E. Rosenzweig and P. Singh (2001): Aria: An Agent for Annotating and Retrieving Images. IEEE Computer, vol. 34, no. 7, pp. 57-62.

Lofland, J. and L.H. Lofland (1995): Analyzing Social Settings: A Guide to Qualitative Observation and Analysis (3rd edn.). Belmont, CA: Wadsworth.

Lutz, C.A. and J.L. Collins (1993): Reading National Geographic. Chicago, IL: University of Chicago Press.

Mynatt, E.D., A. Adler, M. Ito and V.L. O’Day (1997): Design for Networked Communities. In S. Pemberton (ed.): Proceedings of the ACM Conference on Human Factors in Computing Systems, CHI '97, Atlanta, GA, March 22-27, 1997. ACM Press, pp. 210-217.

National Union of Journalists (1996): If you Mac it, mark it! In Proceedings of the http:// media.gn.apc.org/manip.html, 1996.

Rodden, K. and K.R. Wood (2003): How Do People Manage Their Digital Photographs? In Proceedings of the ACM Conference on Human Factors in Computing (CHI '03), Fort Lauderdale, FL, April 5-10, 2003. ACM Press, pp. 409-416.

Sarvas, R., E. Herrarte, A. Wilhelm and M. Davis (2004): Metadata Creation System for Mobile Images. In Proceedings of the 2nd International Conference on Mobile Systems, Applications, and Services (MobiSYS 04), Boston, MA, June 6-9, 2004. ACM Press, pp. 36-48.

Schmidt, K. and L. Bannon (1992): Taking CSCW Seriously: Supporting Articulation Work. Computer Supported Cooperative Work (CSCW): An International Journal, vol. 1, no. 1-2, pp. 7-40.

Smith, M.A. and P. Kollock (eds.). (1999): Communities in Cyberspace. New York, NY: Routledge.

Sontag, S. (1979): On Photography. London, England: Penguin Books Limited.

Strauss, A. (1985): Work and the Division of Labor. The Sociological Quarterly, vol. 26, no. 1, pp. $1-19$.

Strauss, A. and J. Corbin (1990): Basics of Qualitative Research: Grounded Theory Procedures and Techniques. Newbury Park, CA: Sage Publications, Inc. 
Suchman, L. (1994): Do Categories Have Politics? The Language/Action Perspective Reconsidered. Computer Supported Cooperative Work (CSCW): An International Journal, vol. 2, no. 3, pp. 177-190.

von Ahn, L. and L. Dabbish (2004): Labeling Images with a Computer Game. In Proceedings of the ACM Conference on Human Factors in Computing (CHI '04), Vienna, Austria, 24-29 April, 2004. ACM Press, pp. 319-326.

Winograd, T. (1994): Categories, Disciplines, and Social Coordination. Computer Supported Cooperative Work (CSCW): An International Journal, vol. 2, no. 3, pp. 191-197.

Yee, K.-P., K. Swearingen, K. Li and M. Hearst (2003): Faceted Metadata for Image Search and Browsing. In Proceedings of the ACM Conference on Human Factors in Computing (CHI '03), Fort Lauderdale, FL, April 5-10, 2003. ACM Press. 